\title{
JAK2/STAT3-mediated dose-dependent cytostatic and cytotoxic effects of sesquiterpene lactones from Gymnanthemum extensum on A549 human lung carcinoma cells
}

\author{
SIRIPORN KEERATICHAMROEN ${ }^{1}$, KRIENGSAK LIRDPRAPAMONGKOL ${ }^{1,2}$, SANIT THONGNEST $^{3}$, \\ JUTATIP BOONSOMBAT ${ }^{3}$, PORNSUDA CHAWENGRUM ${ }^{4}$, THIWAREE SORNPRACHUM ${ }^{1}$, JITNAPA SIRIRAK ${ }^{5}$, \\ CHRIS VERATHAMJAMRAS ${ }^{1}$, NARITTIRA ORNNORK ${ }^{1}$, SOMSAK RUCHIRAWAT $^{2,4,6}$ and JISNUSON SVASTI ${ }^{1,7}$ \\ ${ }^{1}$ Laboratory of Biochemistry, Chulabhorn Research Institute, Bangkok 10210; ${ }^{2}$ Center of Excellence on Environmental Health \\ and Toxicology, Ministry of Education, Bangkok 10400; ${ }^{3}$ Laboratory of Natural Products, Chulabhorn Research Institute; \\ ${ }^{4}$ Program in Chemical Sciences, Chulabhorn Graduate Institute, Chulabhorn Royal Academy, Bangkok 10210; \\ ${ }^{5}$ Department of Chemistry, Faculty of Science, Silpakorn University, Nakhon Pathom 73000; \\ ${ }^{6}$ Laboratory of Medicinal Chemistry, Chulabhorn Research Institute; ${ }^{7}$ Program in Applied Biological Sciences, \\ Chulabhorn Graduate Institute, Chulabhorn Royal Academy, Bangkok 10210, Thailand
}

Received August 13, 2021; Accepted October 4, 2021

DOI: $10.3892 /$ or.2021.8217

\begin{abstract}
Due to drug resistance and disease recurrence, lung cancer remains one of the primary cancer-related causes of death in both men and women worldwide. In addition, lung cancer is clinically silent and thus most patients are at an advanced stage at the time of diagnosis. The limited efficiency of current conventional chemotherapies necessitates the search for novel effective anticancer agents. The present study demonstrated the anti-proliferative effect and apoptosis-inducing activity of three sesquiterpene lactones isolated from Gymnanthemum extensum, vernodalin (VDa), vernolepin (VLe) and vernolide (VLi), on A549 human lung cancer cells. Treatment with sub-cytotoxic doses (cell viability remaining $>75 \%$ ) of $\mathrm{VDa}$, VLe and $\mathrm{VLi}$, arrested progression of the A549 cell cycle at the $\mathrm{G}_{0} / \mathrm{G}_{1}$ phase, while cytotoxic doses of the three compounds induced $\mathrm{G}_{2} / \mathrm{M}$ phase arrest and apoptosis. Mechanistic studies revealed that VDa, VLe and VLi may exert their anti-tumor activity through the JAK2/STAT3 pathway. Molecular docking analysis confirmed that VDa, VLe and VLi formed hydrogen bonds with the FERM domain of JAK2 protein. Overall, the present study highlighted the
\end{abstract}

Correspondence to: Dr Siriporn Keeratichamroen or Dr Kriengsak Lirdprapamongkol, Laboratory of Biochemistry, Chulabhorn Research Institute, 54 Kamphaeng Phet 6, Talat Bang Khen, Laksi, Bangkok 10210, Thailand

E-mail: siriporn@cri.or.th

E-mail: kriengsak@cri.or.th

Key words: lung cancer, Gymnanthemum extensum, cytotoxicity, cell cycle arrest, apoptosis potential therapeutic value of VDa, VLe and VLi to be further developed as anticancer agents for the treatment of lung cancer.

\section{Introduction}

Globally, lung cancer (cancer derived from the respiratory epithelium) is the most common malignant disease, and considered one of the major causes of cancer-related mortality (1). In 2020, 2.21 million new cases of lung cancer were diagnosed, with an estimated 1.8 million deaths worldwide (2). Lung cancer is the second most common cancer in males and the fourth most common in females in Thailand (3). Despite significant progress in cancer treatment, current conventional chemotherapies have had limited positive effect on patient survival (4). Therefore, there is a need to identify highly effective therapeutic agents to improve the outcome of lung cancer treatment. Medicinal plants have been widely studied for the discovery of new clinically relevant anticancer agents. Numerous chemotherapeutic drugs in clinical use are derived from plants, as well as other natural sources, including microorganisms and marine organisms (5). In Thailand, a variety of herbal plants have been shown to possess medicinal properties, and have been used for medicinal purposes since ancient times; for example, Fah Talai Jone (Andrographis paniculata) for treating infections and other disorders, Turmeric or Khamin Chan (Curcuma longa) for treating peptic ulcers, and Phim Phai Lin (Gymnanthemum extensum) for treating malaria and cancer $(6,7)$.

Gymnanthemum extensum (G. extensum) (syn. Vernonia extensa var. amygdalina, Asteraceae), locally known as 'Phim Phai Lin', is the only member of its genus found in Thailand (8). It is a shrub or subshrub that will typically reach 2-6 $\mathrm{m}$ in height. This species has been used in Thai folk medicine for reducing blood pressure, blood sugar and blood lipids, as well as for the treatment of skin abscess $(9,10)$. 
Previous phytochemical research on members of the genus Gymnanthemum (Vernonia) resulted in the isolation of various biologically active compounds, including sesquiterpene lactones (such as elemanolides, germacranolides, eudesmanolides and guaianolides), steroids, triterpenes and flavonoids $(11,12)$. Sesquiterpene lactones are described as active compounds with a wide variety of biological activities, including anti-fungal, anti-bacterial, insect anti-feedant, anti-trypanosomal, anti-malarial, anti-inflammatory and anticancer properties (13-15).

Although considerable progress has been made in natural product research towards the isolation, structural determination and biological activity of the isolated compounds, little information is available on the molecular mechanisms by which these bioactive constituents mediate their effects. Lung cancer, especially of the non-small cell lung cancer (NSCLC) subtype, is one of the most serious health concerns in Thailand. Therefore, the aim of the present study was to investigate the molecular mechanisms and biological targets of vernodalin (VDa), vernolepin (VLe) and vernolide (VLi), three cytotoxic sesquiterpene lactones isolated from $G$. extensum (16), in A549 human NSCLC cells.

\section{Materials and methods}

Chromatographic extraction of G. extensum sesquiterpenoids. VDa, VLe and VLi were isolated and purified using in-house methods as previously described (16). Briefly, the dried aerial region of $G$. extensum $(1.3 \mathrm{~kg})$ was manually ground and extracted at room temperature successively, using $\mathrm{CH}_{2} \mathrm{Cl}_{2}$, a $\mathrm{CH}_{2} \mathrm{Cl}_{2} / \mathrm{MeOH}$ (1:1) mixture and $\mathrm{MeOH}$. The extracts were filtered and then evaporated to yield $\mathrm{CH}_{2} \mathrm{Cl}_{2}(29.2 \mathrm{~g})$, $\mathrm{CH}_{2} \mathrm{Cl}_{2} / \mathrm{MeOH}(5.4 \mathrm{~g})$ and $\mathrm{MeOH}(50.8 \mathrm{~g})$ extracts. The three active sesquiterpenoids, namely VDa, VLe and VLi, were separated from the $\mathrm{CH}_{2} \mathrm{Cl}_{2}$ extracts of G. extensum by a combination of chromatographic methods and semi-preparative high-performance liquid chromatography purification.

Cell culture and chemicals. The A549 human lung adenocarcinoma cell line was purchased from the American Type Culture Collection (cat. no. CCL-185 ${ }^{\mathrm{TM}}$ ). The cells were cultured in RPMI-1640 medium supplemented with $10 \%$ (v/v) fetal bovine serum and $1 \%(\mathrm{v} / \mathrm{v})$ antibiotic-antimycotic (all from Gibco; Thermo Fisher Scientific, Inc.), and maintained at $37^{\circ} \mathrm{C}\left(5 \% \mathrm{CO}_{2}\right)$ in a humidified atmosphere. The cells were passaged every 3-4 days and morphology was investigated by inverted phase-contrast microscopy. The G. extensum-derived compounds, VDa, VLe and VLi, were dissolved in DMSO, and diluted with culture media to the desired concentrations, while keeping DMSO concentration at $0.2 \%(\mathrm{v} / \mathrm{v})$ throughout the study.

Cell viability assay. The effects of $G$. extensum-derived compounds on the viability of A549 lung cancer cells were assessed using an MTT assay. Various natural products, such as a resveratrol, bergapten and sotetsuflavone, have been reported to exert their biological effects, including cytotoxicity, cell cycle arrest and induction of apoptosis, at a concentration range of 10-100 $\mu \mathrm{M}$ (17-19). In the present study, a concentration range of $10-60 \mu \mathrm{M}$ was selected for VDa, VLe and VLi treatment. Briefly, A549 cells were seeded into 96-well culture plates at a density of $1 \times 10^{4}$ cells/well $(100 \mu \mathrm{l})$. After $24 \mathrm{~h}$, the cells were treated with $100 \mu \mathrm{VDD}$, VLe and VLi at various concentrations $(10,30$ and $60 \mu \mathrm{M})$, or with the vehicle (cell culture medium) for $24 \mathrm{~h}$. The spent medium were replaced with $100 \mu \mathrm{l}$ of fresh culture medium containing $0.5 \mathrm{mg} / \mathrm{ml}$ MTT (Sigma-Aldrich; Merck KGaA) and incubated for $2 \mathrm{~h}$ at $37^{\circ} \mathrm{C}$. Finally, the MTT-containing medium was removed and $100 \mu 1$ DMSO was added to dissolve the formazan crystals. The number of viable cells was determined by measuring the absorbance at $550 \mathrm{~nm}$ and subtracting the absorbance at the reference wavelength $(650 \mathrm{~nm})$, using a microplate reader. The absorbance of the untreated control was taken as $100 \%$, and the decrease in the number of cells treated with the extracts was calculated. Assays were carried out three times with quadruplicate samples.

Apoptosis assay. The apoptotic profiles of A549 cells treated with various concentrations of $G$. extensum-derived compounds were detected using the Muse ${ }^{\circledR}$ Cell Analyzer (Luminex Corporation) as previously described (20). Briefly, cells were harvested after $24 \mathrm{~h}$ of treatment, stained with Muse Annexin V \& Dead Cell kit (Luminex Corporation) for $20 \mathrm{~min}$ in the dark at room temperature, and immediately subjected to apoptosis detection. Results are presented as mean values of total apoptosis [the percentage of early (positive for Annexin V) + late (positive for both Annexin V and 7-AAD) apoptotic cell populations] from three independent experiments.

Cell cycle analysis. Cell cycle progression was investigated by flow cytometric analysis $\left(\right.$ Muse $^{\circledR}$ Cell Analyzer; Luminex Corporation) as previously described (21). Briefly, A549 cells were treated with various concentrations of G. extensum-derived compounds or a specific inhibitor of JAK2/STAT3, cucurbitacin-I (CBC-I), for 24 h. After treatment, the cells were collected, fixed with ice-cold $70 \%$ ethanol and stored at $-20^{\circ} \mathrm{C}$ overnight prior to staining. Then, the cells were washed, stained with $200 \mu 1$ Muse Cell Cycle reagent and subjected to cell cycle analysis. Results are presented as mean values of the percentage of the cells in each phase $\left(\mathrm{G}_{0} / \mathrm{G}_{1}, \mathrm{~S}\right.$ and $\mathrm{G}_{2} / \mathrm{M}$ ) from three independent experiments.

Molecular docking. The protein structure of JAK2 (PDB:4Z32) was acquired from Protein Data Bank (http://www.rcsb.org/), while the molecular structures of VDa, VLe and VLi were obtained from PubChem (https://pubchem.ncbi.nlm.nih.gov). iGEMDOCK v2.1 software (22) was used to perform molecular docking using the accurate docking function (slow docking). All images were generated using UCSF Chimera (23).

Western blot analysis. The expression levels of selected signaling proteins were determined by western blot analysis. Since the aim was to evaluate the mechanisms by which VDa, VLe and VLi lead to cell death, western blot analysis was conducted $4 \mathrm{~h}$ after treatment. Preliminary results indicated that the changes in signaling pathways were detected $4 \mathrm{~h}$ after treatment. At $24 \mathrm{~h}$ post treatment, apoptosis had already taken place, so that the changes in signaling cascades and protein expression may have resulted from the apoptotic process, rather 
than changes that trigger apoptosis. Briefly, $4 \mathrm{~h}$ after treatment, A549 cells were treated with different concentrations of VDa, VLe and VLi $(10,30$ or $60 \mu \mathrm{M})$, were harvested and lysed in cell lysis buffer (MilliporeSigma) supplemented with freshly added protease/phosphatase inhibitor cocktail (Cell Signaling Technology, Inc.). The total protein concentration was measured using a Bradford assay kit (Bio-Rad Laboratories, Inc.); $20 \mu \mathrm{g}$ protein per lane was subjected to $10 \%$ SDS-PAGE and then electrophoretically-transferred to Immobilon-P Transfer Membranes (MilliporeSigma). Each membrane was incubated in 3\% (w/v) BSA (Sigma-Aldrich; Merck KGaA) blocking buffer at room temperature for $1 \mathrm{~h}$, and then probed with the primary antibodies against the following, at $4^{\circ} \mathrm{C}$ overnight: JAK2 (1:500; rabbit, monoclonal; cat. no. 3230), phospho-JAK2 (Y1008; 1:500; rabbit, monoclonal; cat. no. 8082), STAT3 (1:3,000; rabbit, polyclonal; cat. no. 9132), phospho-STAT3 (Y705; 1:250; rabbit, monoclonal; cat. no. 9145), p38 (1:1,000; rabbit, polyclonal; cat. no. 9212), phospho-p38 (T180/Y182; 1:250; rabbit, polyclonal; cat. no. 9211), CDK2 (1:1,000; rabbit, monoclonal; cat. no. 2546), p21 (1:500; rabbit, monoclonal; cat. no. 2947), cyclin B1 (1:1,000; rabbit, polyclonal; cat. no. 4138), Cdc2 (1:1,000; mouse, monoclonal; cat. no. 9116), Bax (1:5,000; rabbit, polyclonal; cat. no. 2772), survivin (1:250; rabbit, polyclonal; cat. no. 2803), myeloid cell leukemia-1 (Mcl-1; 1:250; rabbit, polyclonal; cat. no. 4572) and $\alpha$-tubulin (1:20,000; mouse, monoclonal; cat. no. 3873) (all from Cell Signaling Technology, Inc.). The membrane was washed with TBS-T (Tris-buffered saline, $0.1 \%$ Tween-20) before incubating with the appropriate horseradish peroxidase-conjugated secondary antibody (1:5,000; goat anti-rabbit, monoclonal; cat. no. 7074; Cell Signaling Technology; or 1:5,000; rabbit anti-mouse, polyclonal; cat. no. P0260; Dako; Agilent Technologies, Inc.) for $1 \mathrm{~h}$ at room temperature. The relative protein expression levels were detected by chemiluminescence using the WesternBright ECL detection kit (Advansta, Inc.). Quantification of the bands was performed by densitometry using ImageJ version 1.53k (National Institutes of Health).

Statistical analysis. Experimental values from three independent experiments are presented as the mean \pm standard deviation. The statistical significance between the control and treated groups was evaluated using one-way analysis of variance following by Tukey's multiple comparisons test (GraphPad Prism version 5.0; GraphPad Software, Inc.). $\mathrm{P}<0.05$ was considered to indicate a statistically significant difference.

\section{Results}

Effects of $G$. extensum-derived compounds on A549 cell viability. The cytotoxic effects of VDa, VLe and VLi (Fig. 1A) on the A549 human lung cancer cell line were evaluated by MTT assay at three concentrations (10,30 and $60 \mu \mathrm{M})$. After $24 \mathrm{~h}$ of incubation, VDa, VLe and VLi decreased cell viability in a dose-dependent manner, with VLi being the most potent (Fig. 1B). Comparison of cytotoxic activities indicated that treatments with $30 \mu \mathrm{M}$ VDa, $30 \mu \mathrm{M}$ VLe or $10 \mu \mathrm{M}$ VLi were only marginally cytotoxic ( $80 \%$ viability) and may therefore be considered as sub-cytotoxic doses, while high doses $(60 \mu \mathrm{M}$ for VDa and VLe, and $30 \mu \mathrm{M}$ for VLi) were cytotoxic $(\sim 50 \%$ viability).
A

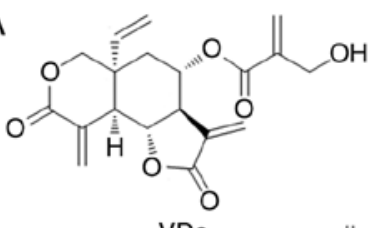
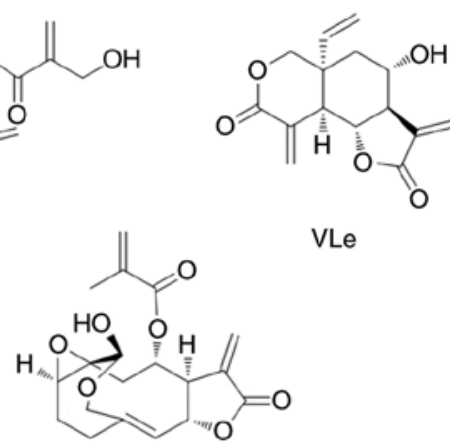

VLe

VLi

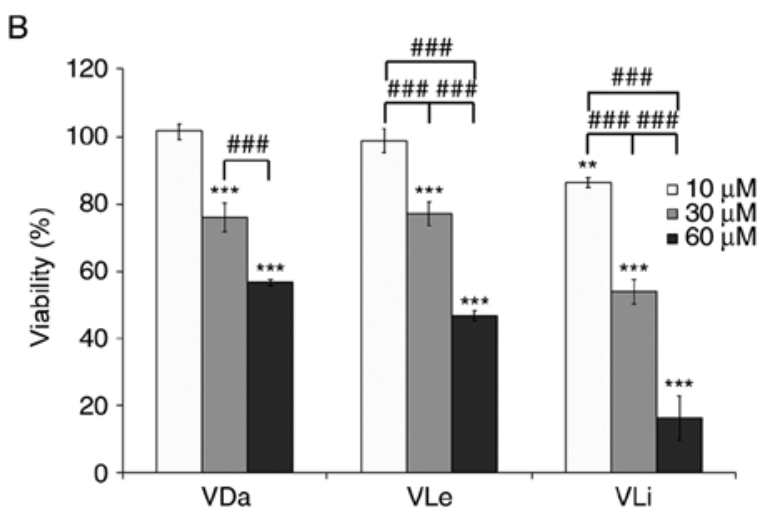

Figure 1. Chemical structure and cytotoxicity of VDa, VLe and VLi. (A) Chemical structure of the investigated compounds. (B) Viability of A549 cells after exposure to the indicated concentrations of VDa, VLe and VLi for $24 \mathrm{~h}$, as determined by MTT assay. Values are presented as the mean \pm SD from three separate experiments. ${ }^{* *} \mathrm{P}<0.01$ and ${ }^{* * * *} \mathrm{P}<0.001$ vs. $10 \mu \mathrm{M} \mathrm{VDa}$.

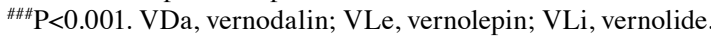

G. extensum-derived compounds induce A549 cell apoptosis. Morphological investigation by inverted phase-contrast microscopy revealed that treatment with VDa, VLe and VLi resulted in a decrease in cell numbers, induction of cell rounding and detachment of cells from the vessel surface (Fig. 2A). In addition, flow cytometric analysis was performed in A549 cells treated with G. extensum-derived compounds for $24 \mathrm{~h}$. The results indicated that after treatment at sub-cytotoxic concentrations for $24 \mathrm{~h}$, the total apoptotic cell population (early + late apoptosis) increased from 5.3 $\pm 0.9 \%$ for the control group to $8.1 \pm 1.8,7.6 \pm 1.2$ and $8.5 \pm 2.6 \%$ for cells treated with VDa, VLe and VLi, respectively. Moreover, treatment of A549 cells with cytotoxic concentrations led to an increase in the total apoptotic cell population to $21.3 \pm 5.4,22.2 \pm 1.6$ and $10.1 \pm 3.6 \%$ for VDa, VLe and VLi, respectively (Fig. 2B and C). In addition, necrotic cell populations were $<1 \%$ following all treatment types and concentrations, suggesting that VDa, VLe and VLi were dose-dependently cytotoxic towards A549 cells through the induction of apoptosis.

Dose-dependent differential effects of $G$. extensum-derived compounds on A549 cell cycle progression. The experimental data demonstrated a decrease in A549 cell number after VDa, VLe and VLi treatment, suggesting that these compounds may exhibit cytostatic effects on A549 cells. To assess the anti-proliferative action of the three compounds, the cell cycle distribution of A549 cells treated with sub-cytotoxic 
A

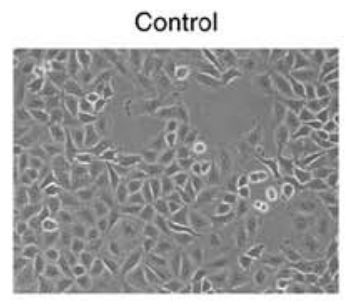

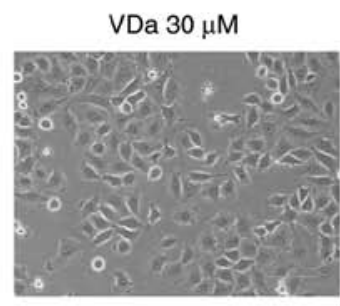

VDa $60 \mu \mathrm{M}$

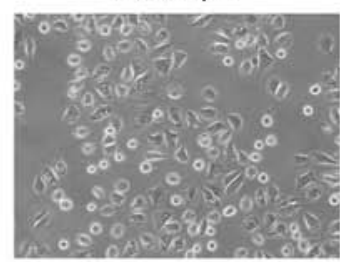

B

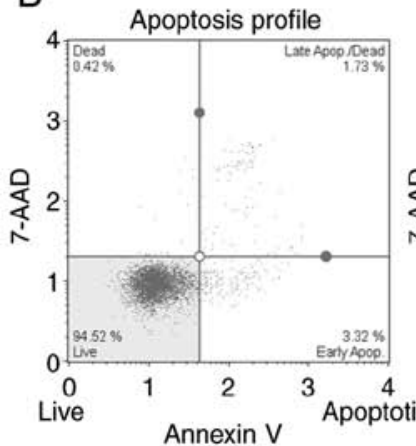

Control

VDa $60 \mu \mathrm{M}$
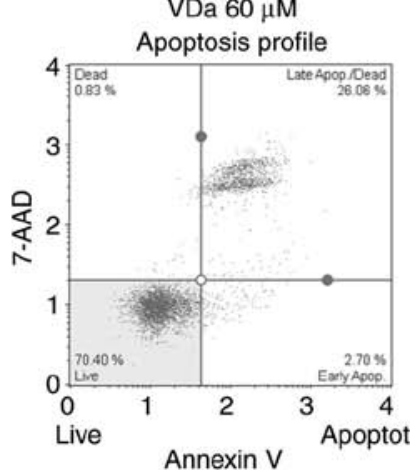

Annexin V
VLe $30 \mu \mathrm{M}$

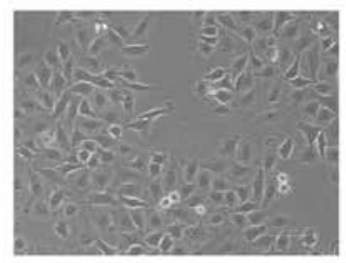

VLe $60 \mu \mathrm{M}$

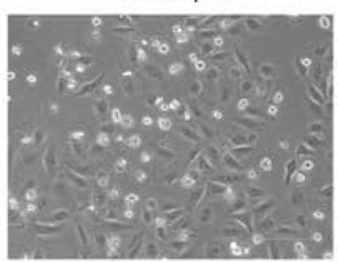

VLe $30 \mu \mathrm{M}$

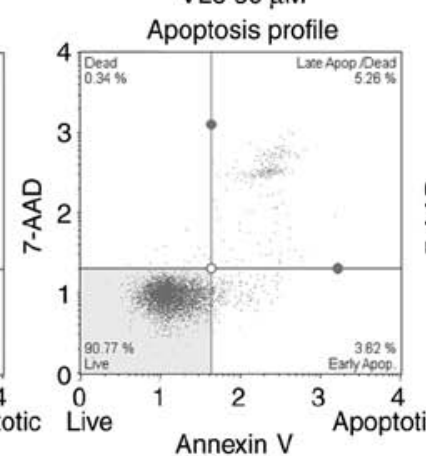

VLe $60 \mu \mathrm{M}$

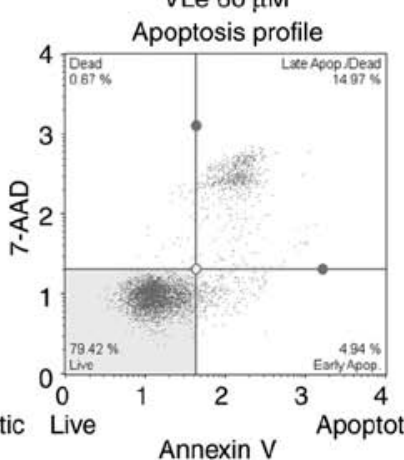

Annexin V
VLi $10 \mu \mathrm{M}$

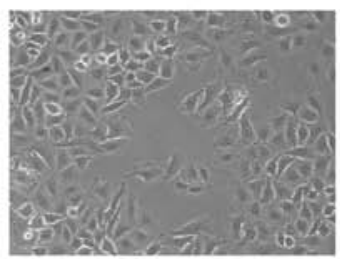

VLi $30 \mu \mathrm{M}$

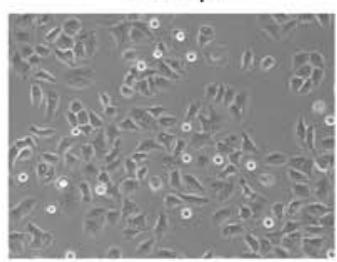

VLi $10 \mu \mathrm{M}$

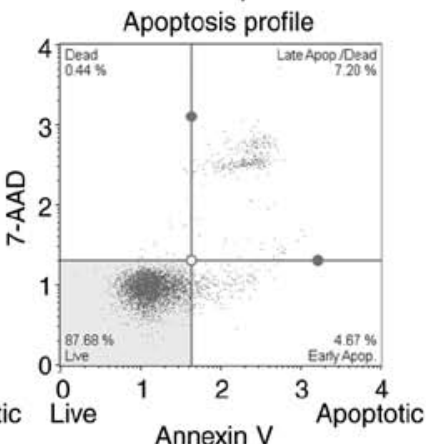

C

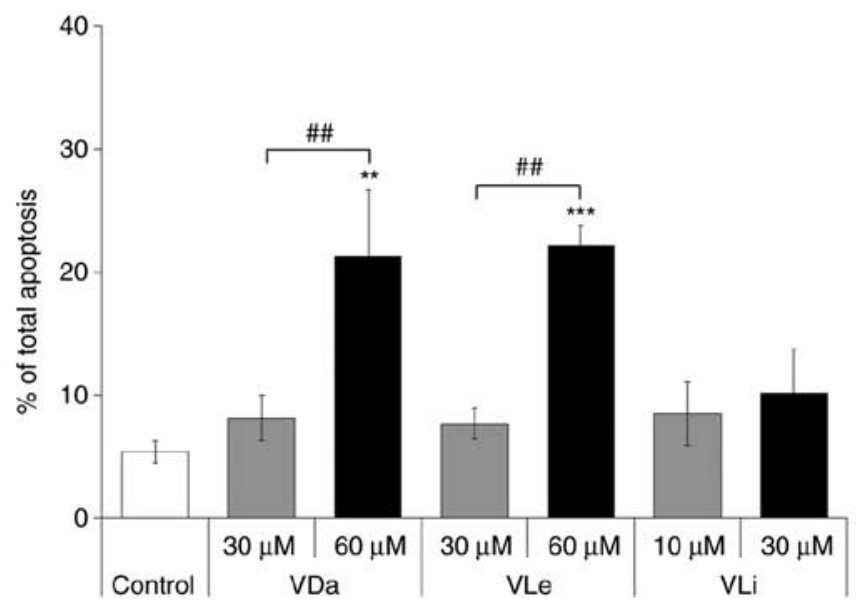

Figure 2. Effects of VDa, VLe and VLi on the morphology and apoptosis of A549 cells. Cells were incubated with sub-cytotoxic and cytotoxic doses of VDa, VLe and VLi for $24 \mathrm{~h}$, and then analyzed for apoptosis induction by Annexin V/7-AAD double staining. (A) Morphological changes of A549 cells treated with vehicle control, VDa, VLe and VLi; magnification, x200. (B) Representative dot plots showing the proportion of viable cells (lower left), early apoptotic cells (lower right), late apoptotic cells (upper right) and necrotic cells (upper left). (C) \% Apoptotic rate (early + late apoptosis) is shown. Results are expressed as the mean $\pm \mathrm{SD}$ from three independent experiments. ${ }^{* *} \mathrm{P}<0.01$ and ${ }^{* * * *} \mathrm{P}<0.001$ vs. the untreated control. ${ }^{\# \#} \mathrm{P}<0.01$. VDa, vernodalin; VLe, vernolepin; VLi, vernolide. 

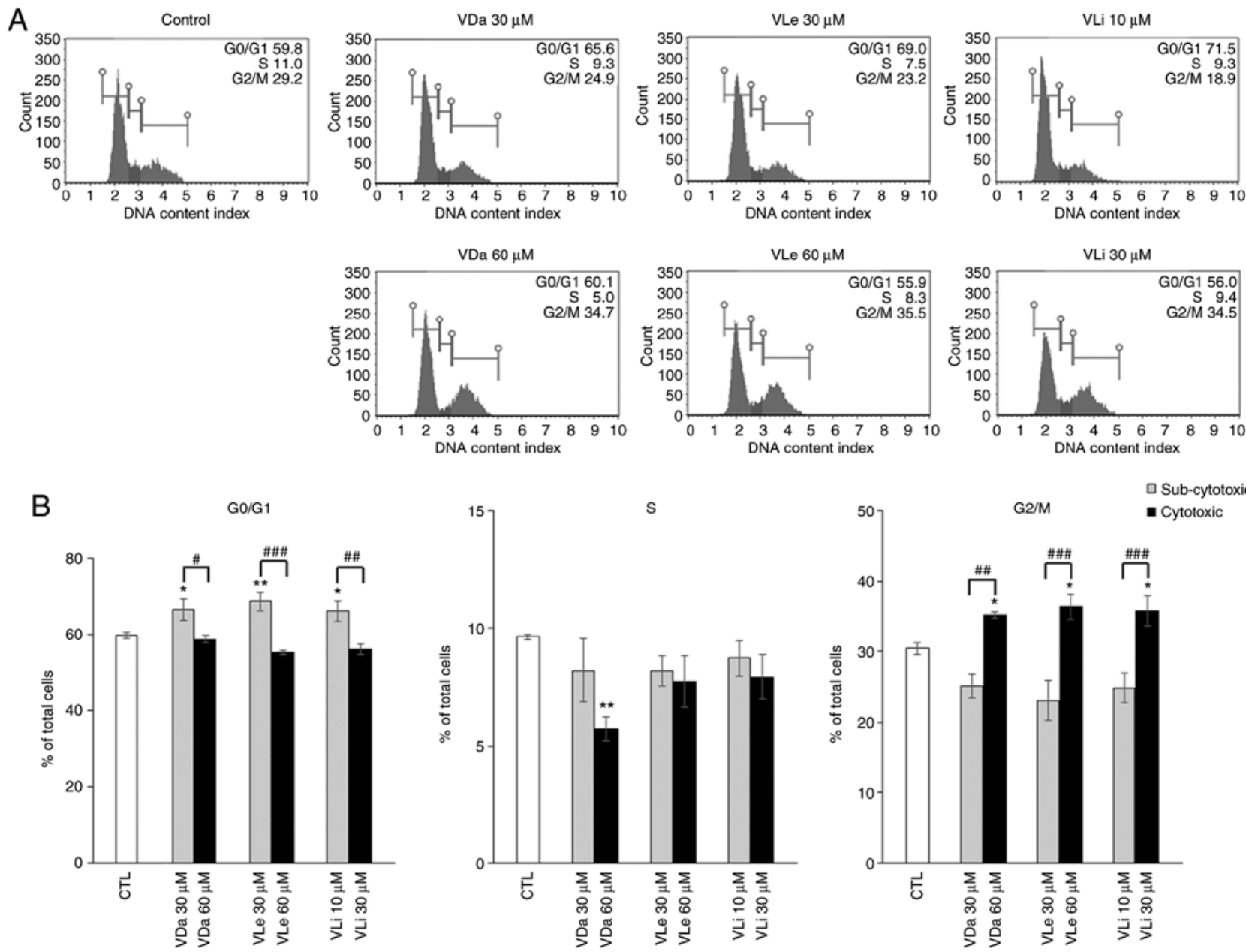

Figure 3. Effects of VDa, VLe and VLi on A549 cell cycle progression. Cell cycle distribution after treatment with VDa, VLe and VLi for $24 \mathrm{~h}$ was assessed using a Muse Cell Analyzer. (A) Representative cell cycle profiles of the untreated control and cells treated with sub-cytotoxic and cytotoxic doses of VDa, VLe and VLi. (B) Histograms showing the effects of VDa, VLe and VLi on A549 cells, where significant arrest of cells was found in the $G_{0} / G_{1}$ phase at sub-cytotoxic doses, and in the $\mathrm{G}_{2} / \mathrm{M}$ cell cycle phase at cytotoxic doses. Values represent the mean $\pm \mathrm{SD}$ from three separate experiments. "P $<0.05$ and ${ }^{* *} \mathrm{P}<0.01$ vs. the untreated control. ${ }^{\#} \mathrm{P}<0.05,{ }^{\# \#} \mathrm{P}<0.01$ and ${ }^{\# \# "} \mathrm{P}<0.001$. VDa, vernodalin; VLe, vernolepin; VLi, vernolide; CTL, control.

and cytotoxic concentrations of VDa, VLe and VLi was investigated by flow cytometry. The results indicated alterations in cell cycle progression in all treatment groups. As shown in Fig. 3, treatment of A549 cells with sub-cytotoxic doses of VDa, VLe and VLi caused a significant increase in the $\mathrm{G}_{0} / \mathrm{G}_{1}$ population to $66.6 \pm 2.8,68.7 \pm 2.5$ and $66.2 \pm 2.6 \%$ for $\mathrm{VDa}, \mathrm{VLe}$ and $\mathrm{VLi}$, respectively, compared with untreated control cells $(59.9 \pm 0.9 \%)$. Consistent with this result, a decrease in the proportion of cells in the $S$ phase $(8.2 \pm 1.3$, $8.2 \pm 0.6$ and $8.7 \pm 0.8 \%$ for $\mathrm{VDa}, \mathrm{VLe}$ and $\mathrm{VLi}$, respectively) and $\mathrm{G}_{2} / \mathrm{M}$ phase $(25.2 \pm 1.6,23.1 \pm 2.9$ and $24.8 \pm 2.2 \%$ for $\mathrm{VDa}$, VLe and VLi, respectively) of the cell cycle was observed, compared with the control $(9.6 \pm 0.1 \%$ for $\mathrm{S}$ and $30.5 \pm 0.8 \%$ for $\mathrm{G}_{2} / \mathrm{M}$ phase, respectively).

However, increasing the concentration of VDa, VLe and $\mathrm{VLi}$ to cytotoxic doses resulted in a significant increase in the percentage of cells in the $\mathrm{G}_{2} / \mathrm{M}$ phase (35.2 $\pm 0.5,36.4 \pm 1.7$ and $35.8 \pm 2.1 \%$ for $\mathrm{VDa}, \mathrm{VLe}$ and $\mathrm{VLi}$, respectively) compared with untreated control cells. The increased number of cells in the $\mathrm{G}_{2} / \mathrm{M}$ phase was accompanied by a proportional decrease in the $\mathrm{G}_{0} / \mathrm{G}_{1}$ cell populations $(58.8 \pm 1.0,55.3 \pm 0.6$ and $56.1 \pm 1.4 \%$ for $\mathrm{VDa}, \mathrm{VLe}$ and $\mathrm{VLi}$, respectively) and $\mathrm{S}$ phase populations
(5.7 $\pm 0.5,7.7 \pm 1.1$ and $7.9 \pm 0.9 \%$ for $\mathrm{VDa}, \mathrm{VLe}$ and $\mathrm{VLi}$, respectively), compared with the control group. These data suggest that VDa, VLe and VLi exerted dose-related cytostatic effects on A549 cells, resulting in inhibition of cellular proliferation.

Molecular docking study. The chemical structures of the G. extensum-derived compounds are related to pathenolide, a sesquiterpene lactone which has been shown to inhibit JAK2/STAT3 signaling (24). Therefore, a molecular docking study was performed using iGEMDOCK v2.1 software to investigate whether JAK2 is a molecular target of VDa, VLe and VLi. As revealed in Fig. 4, the binding positions of VDa (purple) and VLe (deep blue) in JAK2 are located between the F1 and F3 lobes of the FERM domain, while VLi (sky blue) is bound between the F1 and F2 lobes of the FERM domain. The binding energies of VDa, VLe and VLi were -88.04, -82.81 and -89.54 $\mathrm{kcal} / \mathrm{mol}$, respectively (Table I). VDa formed hydrogen bonds with amino acids of FERM F1 domain (GLU65, ASN83 and PHE85) and linker (ASN395) (Fig. 5A) whereas VLe formed hydrogen bonds with amino acids of the FERM F1 domain (ASN83 and ALA86) and the FERM F3 domain (SER367 and ARG374) (Fig. 5B). However, VLi, which had the lowest binding 


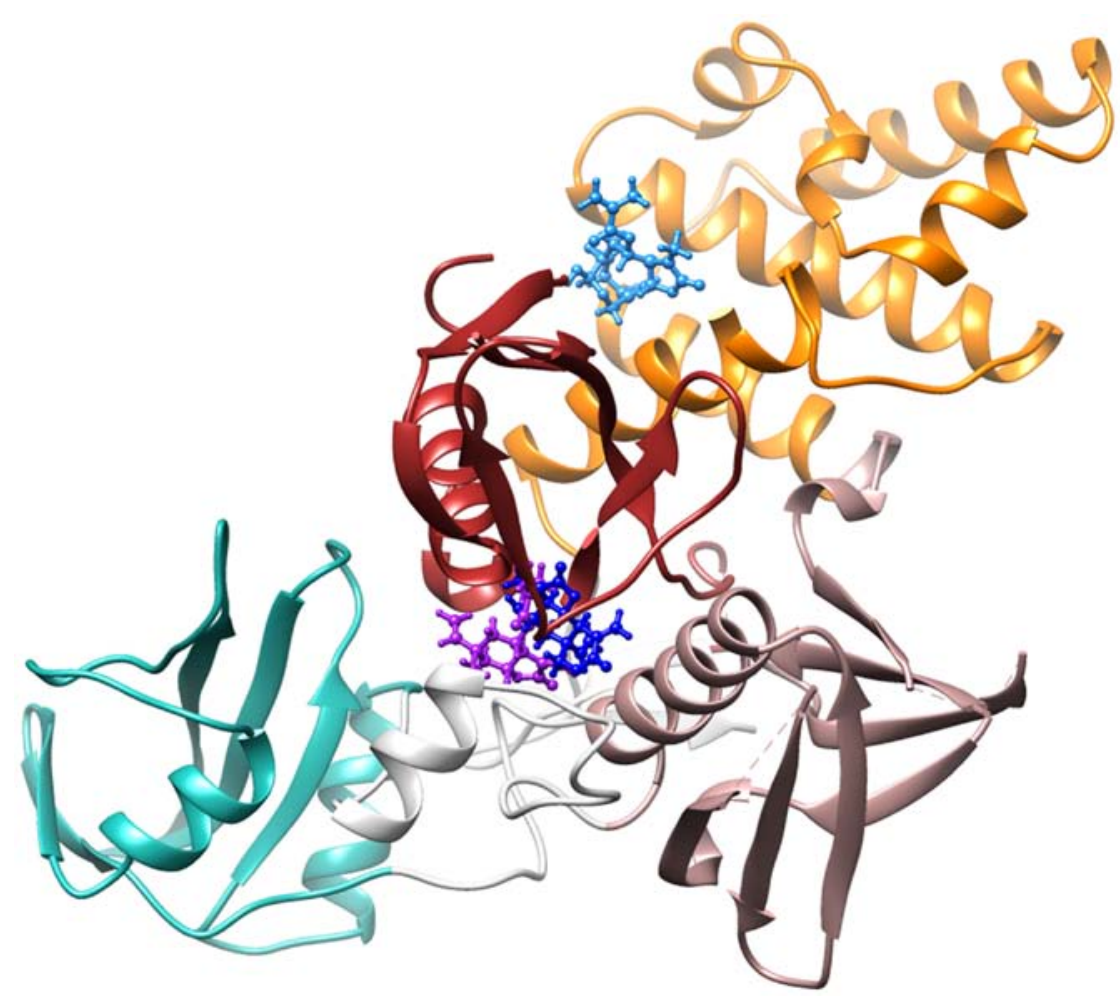

Figure 4. Binding positions of vernodalin (purple), vernolepin (deep blue) and vernolide (sky blue) in the cavity of JAK2 (PDB ID: 4Z32), where the Src homology 2 domain of JAK2 is shown in green, the linker is shown in white and the F1, F2 and F3 lobes of the FERM domain are shown in red, orange and rose gold, respectively.

energy, formed hydrogen bonds with amino acids of FERM F1 domain (SER50 and GLU51) and FERM F2 domain (ARG158 and HIS159) of JAK2 (Fig. 5C). These results suggested that the JAK2 may be the target of VDa, VLe and VLi.

Effects of $G$. extensum-derived compounds on protein expression. To gain further insight into the mechanisms underlying the cytostatic and cytotoxic effects induced by VDa, VLe and VLi, the expression levels of signaling molecules associated with JAK2/STAT3 signaling, cellular stress response, cell cycle regulation and apoptosis were assessed. Western blot analysis indicated that treatment with VDa, VLe and VLi suppressed the levels of p-JAK2 and p-STAT3, and increased p-p38 levels in A549 cells, in a dose-dependent manner (Fig. 6A). These results are consistent with the ability of the three compounds to bind JAK2, as determined by the molecular docking study.

The levels of cell cycle regulatory proteins were also investigated. Treatment of A549 cells with sub-cytotoxic doses of VDa, VLe and VLi resulted in lower expression levels of CDK2, a $\mathrm{G}_{1} / \mathrm{S}$-specific CDK, and upregulated expression of a CDK inhibitor p21 (Fig. 6A). When cytotoxic doses of the three compounds were employed, the decreased levels of $\mathrm{G}_{2} / \mathrm{M}$-specific cyclin and $\mathrm{CDK}$, cyclin B1 and Cdc2, were observed in the treated cells (Fig. 6A). Furthermore, Bax, the pro-apoptotic protein, was upregulated in cells treated with VDa, VLe and VLi compared with the untreated control, while the decreased levels of the anti-apoptotic proteins, survivin and Mcl-1, were detected in a dose-dependent manner (Fig. 6A). These results indicated that exposure of A549 cells to VDa, VLe and VLi induced changes in the expression levels of signaling molecules associated with the suppression of cell proliferation, increased stress and enhanced apoptosis.

$J A K 2 / S T A T 3$ inhibitor reproduces the effects of G. extensum-derived compounds in A549 cells. A specific inhibitor of JAK2/STAT3, CBC-I, was used to confirm whether the effects of VDa, VLe and VLi on A549 cells were mediated through the inhibition of JAK2/STAT3 signaling. Cell cycle analysis indicated that the cell population tended to shift to $\mathrm{G}_{0} / \mathrm{G}_{1}$ and $\mathrm{G}_{2} / \mathrm{M}$ phase arrest when treated with 10 and $50 \mu \mathrm{M}$ CBC-I, respectively, similar to that observed with sub-cytotoxic and cytotoxic treatments of G. extensum-derived compounds (Table II). Western blot analysis revealed that treatment with CBC-I decreased the levels of p-JAK2, p-STAT3, survivin and Mcl-1, but caused increased phosphorylation of p38 (Fig. 6B). Treatment with $10 \mu \mathrm{M}$ CBC-I resulted in a slight downregulation of $\mathrm{CDK} 2$ and an upregulation of p21. However, cells treated with $50 \mu \mathrm{M}$ of CBC-I exhibited markedly decreased levels of cyclin B1 and Cdc2 (Fig. 6B). Collectively, these findings revealed similar tendencies in the effects of treatment with G. extensum-derived compounds and treatment with the JAK2/STAT3 inhibitor, CBC-I, suggesting the involvement of the JAK2/STAT3 pathway in actions of VDa, VLe and VLi.

\section{Discussion}

VDa, VLe and VLi, three bioactive constituents isolated from $G$. extensum, have been reported to possess various pharmacological activities. Our previous study demonstrated $\mathrm{G}_{2} / \mathrm{M}$ cell cycle arrest and apoptosis induction in HepG2 liver 
Table I. Summary of the binding energy, amino acid interactions and hydrogen bond length of VDa, VLe and VLi in the binding site of JAK2.

\begin{tabular}{lllr}
\hline Compounds & Binding energy, kcal/mol & \multicolumn{1}{c}{ Amino acid residue } & Hydrogen bond length, \\
\hline VDa & -88.04 & GLU65, ASN83, PHE85, ASN395 & $2.35,1.73,2.18,2.81$ \\
VLe & -82.81 & ASN83, ALA86, SER367, ARG374 & $2.41,2.62,2.69,2.84$ \\
VLi & -89.54 & SER50, GLU51, ARG158, HIS159 & $2.89,2.90,2.53,2.60$ \\
\hline
\end{tabular}

VDa, vernodalin; VLe, vernolepin; VLi, vernolide.
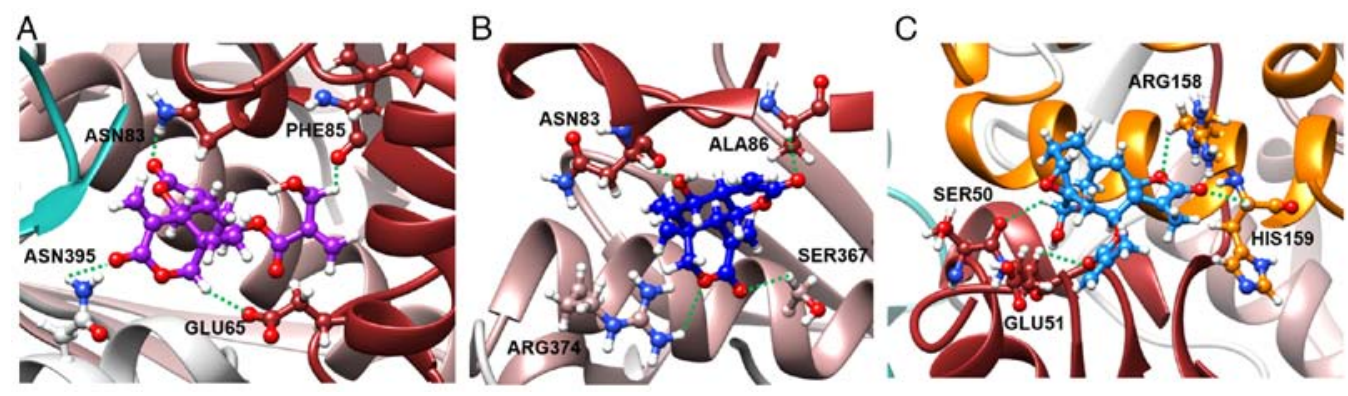

Figure 5. Hydrogen bond interactions observed in the binding of (A) vernodalin, (B) vernolepin and (C) vernolide in the cavity of JAK2 (PDB ID: 4Z32).

A

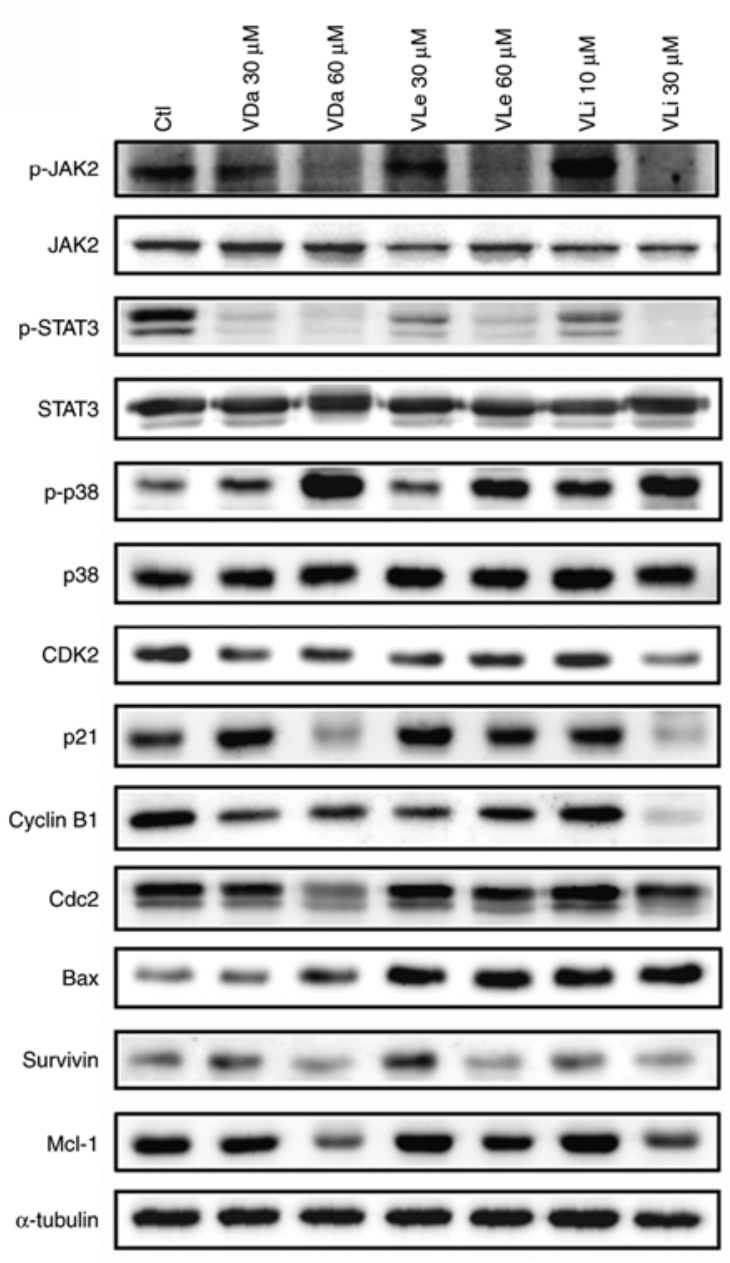

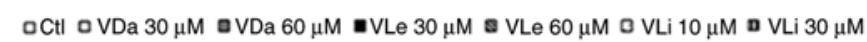
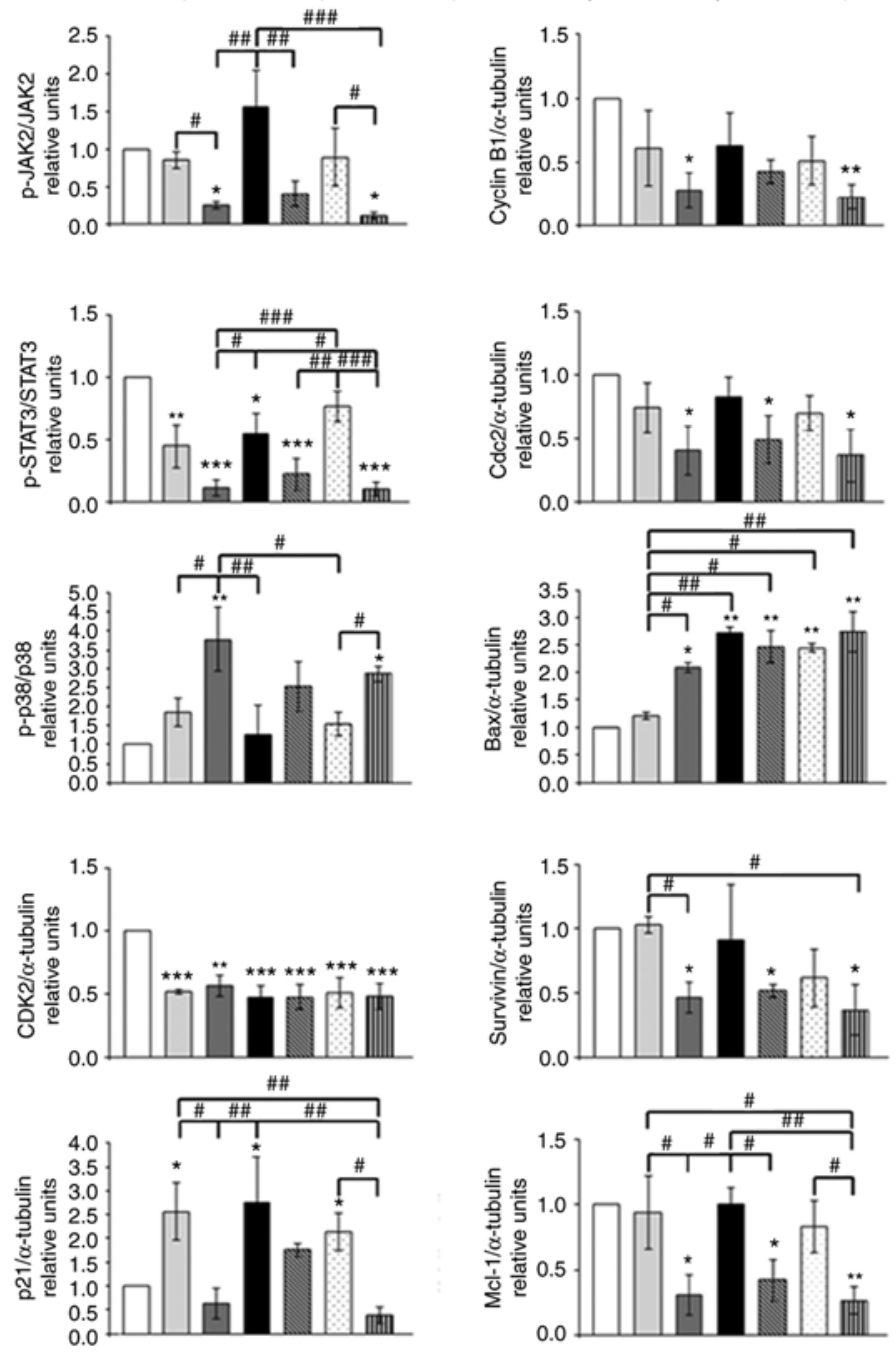
B
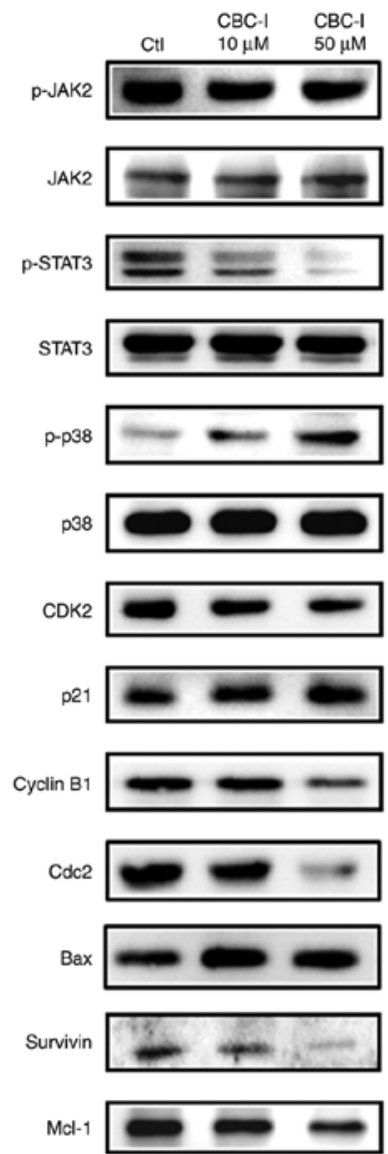

$\alpha-$ tubulin

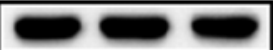

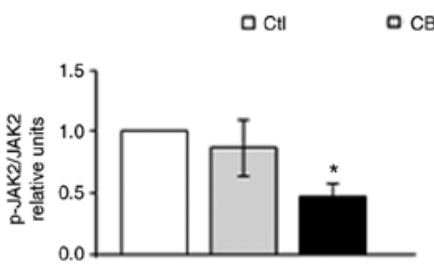
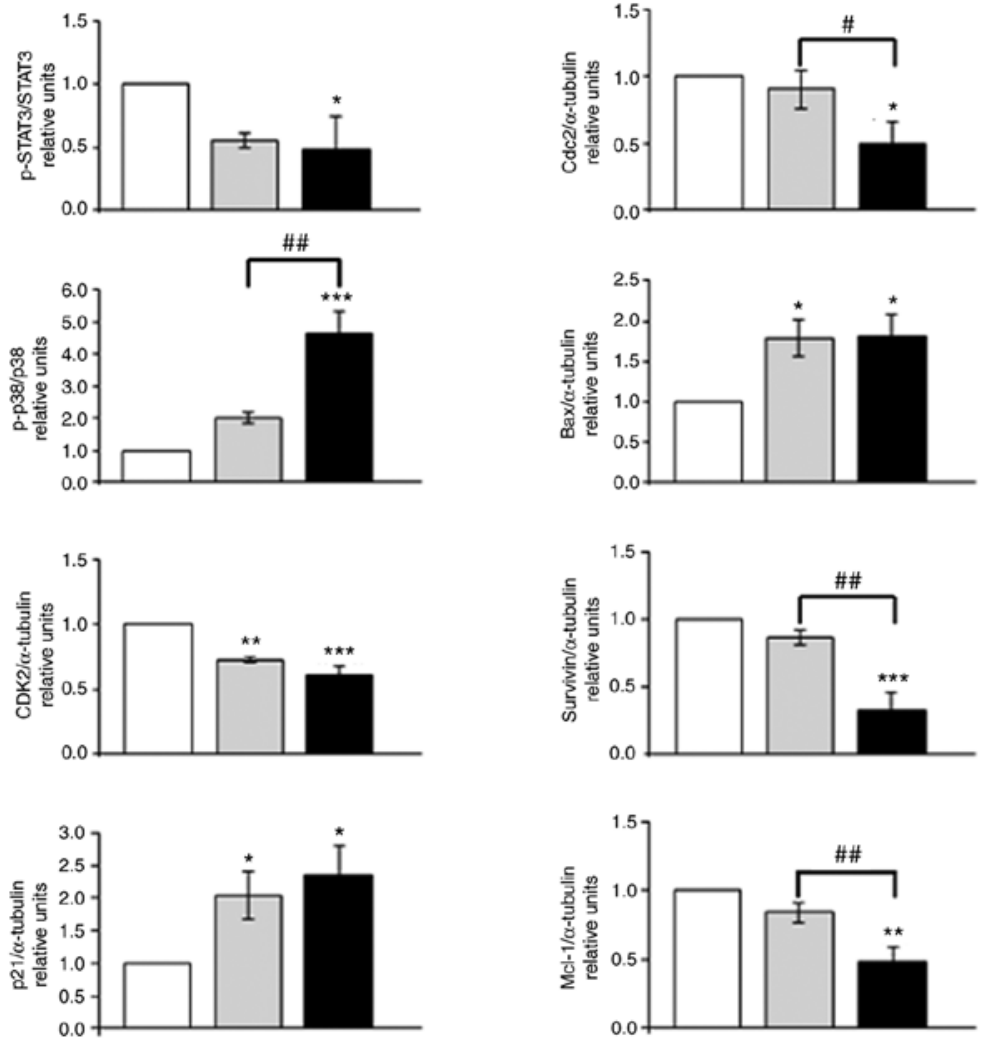

Figure 6. Western blot and quantitative analysis showing the effects of G. extensum-derived compounds on A549 cells. (A) Effects of VDa, VLe and VLi on the expression of JAK2/STAT3 signaling, cellular stress proteins and proteins involved in cell cycle regulation and apoptosis. (B) Effects of a specific inhibitor of JAK2/STAT3 signaling (CBC-I) on the expression of proteins related to cellular stress, cell cycle regulation and apoptosis. Representative blots from at least three separate experiments are shown. Expression of phosphorylated forms of proteins was normalized with respect to the corresponding non-phosphorylated forms. All other proteins were normalized to the loading control. Values are presented as the mean \pm SD from three independent experiments. ${ }^{*} \mathrm{P}<0.05,{ }^{* *} \mathrm{P}<0.01$ and ${ }^{* * *} \mathrm{P}<0.001$ vs. the untreated control. ${ }^{\#} \mathrm{P}<0.05,{ }^{\# \#} \mathrm{P}<0.01$ and ${ }^{\# \# \#} \mathrm{P}<0.001$. VDa, vernodalin; VLe, vernolepin; VLi, vernolide; Ctl, control; Mcl-1myeloid cell leukemia-1; G. extensum, Gymnanthemum extensum.

cancer cells after VDa, VLe and VLi treatment (16), but the molecular mechanism and biological target were not identified. Kupchan et al (25) demonstrated the anti-tumor activity of VDa against KB cells, and reported both the in vitro cytotoxicity and the in vivo tumor inhibitory activity of VLe (26). In addition to the anticancer effect, other biological activities of VDa, VLe and VLi have been reported; for example, the platelet anti-aggregating, anti-trypanosomal, anti-inflammatory and irreversible DNA polymerase inhibitory activities of VLe $(27,28)$. Previous studies have also indicated the anti-plasmodial activity of VDa and VLi (29). Moreover, VLi was shown to exhibit cytotoxicity and bactericidal activity against gram-positive bacteria, as well as anti-fungal activity (30).

Earlier reports have shown that numerous phytochemicals exert their anticancer activities through the inhibition of proliferation and the induction of apoptosis (31). Apoptosis (or programmed cell death) plays an essential role in various biological events, including organism development and maintenance of homeostasis. However, cancer cells may lose their ability to undergo apoptosis, resulting in therapeutic resistance and cancer recurrence (32). Therefore, natural compounds that induce apoptosis may represent promising anticancer agents. The present study evaluated the mechanism underlying the anticancer activity of VDa, VLe and VLi on human A549 lung cancer cells.

Herein, the cytotoxicity, cytostatic activity and apoptosis-inducing ability of VDa, VLe and VLi were investigated. The results demonstrated that VDa, VLe and VLi exerted cytotoxic effects by promoting apoptosis. The number of apoptotic cells increased in cells treated with VDa, VLe and VLi compared with untreated cells, corresponding with the increase in concentration. However, the percentage of apoptotic cells was lower than expected, suggesting that cell cycle arrest may have occurred, ultimately inhibiting cellular proliferation. This hypothesis is supported by the cell cycle distribution results. Cytostatic induction can be considered a relevant mechanism to inhibit, delay or reverse tumor progression (33). The present study results demonstrated that VDa, VLe and VLi possessed cytostatic effects by inhibiting cellular proliferation 
Table II. Cell cycle progression of A549 cells treated with the JAK2/STAT3 inhibitor, CBC-I.

Cell cycle distribution, $\%$

\begin{tabular}{lccr}
\cline { 2 - 4 } Treatment & $\mathrm{G}_{0 /} \mathrm{G}_{1}$ & $\mathrm{~S}$ & $\mathrm{G}_{2} / \mathrm{M}$ \\
\hline Control & $59.9 \pm 0.9$ & $9.6 \pm 0.1$ & $30.5 \pm 0.8$ \\
STAT3-specific inhibitor & & & $29.7 \pm 1.2$ \\
CBC-I $10 \mu \mathrm{M}$ & $63.0 \pm 1.7$ & $7.0 \pm 0.6$ & $43.0 \pm 4.0$ \\
CBC-I $50 \mu \mathrm{M}$ & $47.5 \pm 4.1$ & $8.8 \pm 0.2$ & \\
\hline
\end{tabular}

CBC-I, cucurbitacin-I.

through cell cycle arrest, at either the $G_{0} / G_{1}$ or $G_{2} / M$ phase, depending on the concentrations of the compound used. VDa, VLe and VLi induced $\mathrm{G}_{0} / \mathrm{G}_{1}$-phase block at sub-cytotoxic doses, and $\mathrm{G}_{2} / \mathrm{M}$-phase block at cytotoxic doses, indicating that A549 cells respond to different doses of VDa, VLe and VLi through differences in the activation of signaling pathways, depending on the degree of cellular damage. Similarly, Zhu et al (34) described the dose-dependent differential effects of cryptolepine on A549 cell cycle progression, by arresting cells in the $\mathrm{G}_{0} / \mathrm{G}_{1}$ phase at the concentrations of $1.25-2.5 \mathrm{mM}$, while causing $S$ and $\mathrm{G}_{2} / \mathrm{M}$ arrest at $2.5-5 \mathrm{mM}$.

The STAT3 signaling cascade plays a key role in important cellular events, including cancer cell proliferation, survival, angiogenesis and metastasis (35). Constitutive activation of JAK2, the major upstream kinase of STAT3, has been associated with numerous cancer types (36), including the A549 human lung cancer cells used in the present study. Therefore, JAK2 is a promising target for the development of cancer treatments. Parthenolide, a structurally related sesquiterpene lactone, has been shown to inhibit STAT3 signaling by directly interacting with JAK2 (24). Therefore, docking-based virtual screening was then performed in the current study to predict the interactions between JAK2 (PDB:4Z32) and the three compounds, and to reveal the protein-ligand complex structure. The results showed that VDa, VLe and VLi interacted with JAK2 through hydrogen bonding with amino acid residues located in the FERM domain. The strongest cytotoxic activity among the three compounds was exerted by $\mathrm{VLi}$, which may be explained by its low binding energy to JAK2. These findings suggested that the JAK2/STAT3 signaling may be the target of the G. extensum-derived compounds.

Western blot analysis indicated that in A549 cells, VDa, VLe and VLi inhibited the phosphorylation of JAK2 and STAT3 in a dose-dependent manner. Therefore, the results suggested that VDa, VLe and VLi directly interacted with JAK2 and inactivated its kinase activity, causing suppression of STAT3 phosphorylation. Numerous reports indicated the involvement of STAT3 inactivation in cell cycle arrest and apoptosis (37). Downregulation of STAT3 has been shown to induce $\mathrm{G}_{1}$-phase arrest and apoptosis in esophageal carcinoma ECA109 cells (38). In addition, numerous studies have revealed the association of p38 MAP kinase activation with cellular stress and cell cycle arrest (39). Kang et al (40) demonstrated that p38 MAPK activation mediates tetrahydrocurcumin-induced
$\mathrm{G}_{2} / \mathrm{M}$ arrest and apoptosis in human breast cancer cells. Consistent with these data, the present study showed decreased phosphorylation of STAT3 and increased p38 phosphorylation, concurrent with cell cycle inhibition and apoptosis induction. Notably, the results demonstrated dose-related cell cycle checkpoint activation of A549 cells in response to VDa, VLe and VLi treatment, indicating that the level of activation may be the key element determining the cellular response.

It is well documented that cell cycle arrest is associated with the inhibition of activities of different CDK complexes. The present study demonstrated an increased level of CDK inhibitor, p21, together with decreased CDK2 levels in cells treated with sub-cytotoxic doses of VDa, VLe and VLi, resulting in $G_{0} / G_{1}$ arrest. Similar results have reported that apigenin induced $\mathrm{G}_{0} / \mathrm{G}_{1}$ cell cycle arrest through $\mathrm{CDK} 2 \mathrm{kinase}$ inhibition and induction of p21/WAF1 (41). Furthermore, a previous study demonstrated that CRISPR/Cas9-mediated knockout of CDK2 induced $\mathrm{G}_{0} / \mathrm{G}_{1}$ phase arrest and apoptosis in A375 cells (42). In the present study, upon treatment with cytotoxic doses of VDa, VLe and VLi, stronger inactivation of JAK2/STAT3 pathway caused lower expression of the downstream targets involved in the cell cycle, such as cyclin $B 1$ and $\mathrm{Cdc} 2$, leading to $\mathrm{G}_{2} / \mathrm{M}$ cell cycle arrest. This was consistent with another study describing that Adriamycin-induced $\mathrm{G}_{2} / \mathrm{M}$ arrest was associated with the phosphorylation of $\mathrm{Cdc} 2$ and inactivation of the cyclin B1-Cdc2 complex (43). Additionally, emerging evidence has demonstrated that VLi is a potent inhibitor of STAT3 and $\mathrm{NF}-\kappa \mathrm{B}$, causing arrest of the prostate cancer cell line DU45 at the $S$ phase (44).

Numerous studies have indicated that apoptosis can be mediated by numerous regulatory pathways and molecules. The present results revealed that apoptosis induction by $G$. extensum-derived compounds was associated with increased expression of the pro-apoptotic protein, Bax, and decreased levels of anti-apoptotic proteins, survivin and Mcl-1. It is evident that the STAT3 signaling pathway regulates the expression of a wide variety of genes, including the anti-apoptotic genes, Bcl-XL, Mcl-1 and survivin (45). Experimental evidence has revealed a direct association between STAT3 inhibition and downregulation of Mcl-1 in A549 cells, which further supports the results of the present study (46). The implication of JAK2/STAT3 signaling in the cytostatic and cytotoxic effects of VDa, VLe and VLi was confirmed by the results of JAK2/STAT3 inhibitor treatment. Similar increased 
or decreased levels of signaling molecules associated with cell cycle arrest and apoptosis were detected upon CBC-I treatment, indicating that the JAK2/STAT3 pathway may be a critical mediator of the regulatory effects of VDa, VLe and VLi.

Chemoresistance is one of the major challenges for cancer treatment, including lung cancer. Accumulating evidence suggests that STAT3 plays important roles in the chemoresistance of numerous cancer types to several standard therapeutics (47). Although the present study did not investigate the effect of the three compounds on the chemoresistance of cancer cells, the compounds maybe useful for sensitizing drug-resistant cells to chemotherapy. Since VDa, VLe and VLi can inhibit STAT3 activation, they may be able to reverse STAT3-mediated chemoresistance. Lankadasari et al (48) have shown that blockage of STAT3 activation results in enhanced anti-tumor efficacy of gemcitabine in pancreatic cancer cells. Treatment with VDa, VLe and VLi in combination with commonly used chemotherapeutic drugs, may provide an approach to overcome drug resistance, which should be further investigated. The present study focused on elucidating the molecular targets and mechanism underlying VDa, VLe and VLi activity in A549 lung cancer cells. Additional studies using different types of cancer cell lines, such as multidrug resistance cells, will be required to confirm whether VDa, VLe and VLi, with their ability to inhibit STAT3, can be used as potential candidates to overcome drug resistance.

In conclusion, the results of the present study indicated that VDa, VLe and VLi exerted dose-dependent cytostatic and cytotoxic effects on A549 cells through the JAK2/STAT3 signaling pathway. The study provided detailed evidence for the potential therapeutic value of VDa, VLe and VLi for further development as chemopreventative or chemotherapeutic agents for treatment of lung cancer. To the best of our knowledge, this is the first in-depth report of the anti-tumor mechanisms of VDa, VLe and VLi isolated from G. extensum in human lung cancer cells.

\section{Acknowledgements}

Not applicable.

\section{Funding}

The present study was supported by the Thailand Science Research and Innovation, Chulabhorn Research Institute (grant no. 302/2205).

\section{Availability of data and materials}

The datasets used and/or analyzed during the current study are available from the corresponding author on reasonable request.

\section{Authors' contributions}

SK performed the experiments and wrote the manuscript. KL designed the study and interpreted the results. ST and JB extracted and purified the compounds as well as wrote and revised the manuscript. PC helped with compound preparation. TS and NO performed Western blot analysis. JSi performed the molecular docking study. CV performed the statistical analysis. SR and JSv contributed to the conception of the work, supervised the study design and gave final approval of the manuscript prior to submission. SK and KL confirm the authenticity of all the raw data. All authors read and approved the final manuscript.

\section{Ethics approval and consent to participate}

Not applicable.

\section{Patient consent for publication}

Not applicable.

\section{Competing interests}

The authors declare that they have no competing interests.

\section{References}

1. Ferlay J, Soerjomataram I, Dikshit R, Eser S, Mathers C, Rebelo M, Parkin DM, Forman D and Bray F: Cancer incidence and mortality worldwide: Sources, methods and major patterns in GLOBOCAN 2012. Int J Cancer 136: E359-E386, 2015.

2. World Health Organization (WHO): Fact Sheet Cancer, 2021. WHO, Geneva, 2021. https://www.who.int/news-room/ fact-sheets/detail/cancer. Accessed August 8, 2021.

3. Chien N, Chen JY, Chen SJ and Chang YC: The third Asian radiology forum: Screening programs in Asia. Korean J Radiol 21: 119-124, 2020.

4. Denisenko TV, Budkevich IN and Zhivotovsky B: Cell death-based treatment of lung adenocarcinoma. Cell Death Dis 9: 117, 2018.

5. Cragg GM and Newman DJ: Plants as a source of anti-cancer agents. J Ethnopharmacol 100: 72-79, 2005.

6. Prucksunand $C$, Indrasukhsri $B$, Leethochawalit $M$ and Hungspreugs K: Phase II clinical trial on effect of the long turmeric (Curcuma longa Linn) on healing of peptic ulcer. Southeast Asian J Trop Med Public Health 32: 208-215, 2001.

7. Toyang NJ and Verpoorte R: A review of the medicinal potentials of plants of the genus Vernonia (Asteraceae). J Ethnopharmacol 146: 681-723, 2013.

8. Smitinand T: Thai plant names (Botanical Names-Vernacular Names). Rong pim Buddha press, Bangkok, pp 280, 2014.

9. Egharevba C, Osayemwenre E, Imieje V, Ahomafor J, Akunyuli C, Udu-Cost AA, Theophilus O, James O, Ali I and Falodun A: Significance of bitter leaf (Vernonia amagdalina) in tropical diseases and beyond: A review. Malar Chemoth Cont 3: 120,2014

10. Ong KW, Hsu A, Song L, Huang D and Tan BK: Polyphenols-rich Vernonia amygdalina shows anti-diabetic effects in streptozotocin-induced diabetic rats. J Ethnopharmacol 133: 598-607, 2011.

11. Quasie O, Zhang YM, Zhang HJ, Luo J and Kong LY: Four new steroid saponins with highly oxidized side chains from leaves of Vernonia amygdalina. Phytochem Lett 15: 16-20, 2016.

12. Igual MO, Martucci ME, Da Costa FB and Gobbo-Neto L: Sesquiterpene lactones, chlorogenic acids and flavonoids from leaves of Vernonia polyanthes less (Asteraceae). Biochem Syst Ecol 51: 94-97, 2013.

13. Chea A, Hout S, Long C, Marcourt L, Faure R, Azas N and Elias R: Antimalarial activity of sesquiterpene lactones from vernonia cinerea. Chem Pharm Bull (Tokyo) 54: 1437-1439, 2006.

14. Youn UJ, Park EJ, Kondratyuk TP, Simmons CJ, Borris RP, Tanamatayarat P, Wongwiwatthananukit S, Toyama O, Songsak T, Pezzuto JM and Chang LC: Anti-inflammatory sesquiterpene lactones from the flower of vernonia cinerea. Bioorg Med Chem Lett 22: 5559-5562, 2012.

15. Chen QF, Liu ZP and Wang FP: Natural sesquiterpenoids as cytotoxic anticancer agents. Mini Rev Med Chem 11: 1153-1164, 2011. 
16. Thongnest $S$, Chawengrum $P$, Keeratichamroen $S$ Lirdprapamongkol K, Eurtivong C, Boonsombat J, Kittakoop P, Svasti J and Ruchirawat S: Vernodalidimer L, a sesquiterpene lactone dimer from Vernonia extensa and anti-tumor effects of vernodalin, vernolepin, and vernolide on HepG2 liver cancer cells. Bioorg Chem 92: 103197, 2019.

17. Yuan L, Zhang Y, Xia J, Liu B, Zhang Q, Liu J, Luo L, Peng Z, Song $\mathrm{Z}$ and $\mathrm{Zhu} \mathrm{R}$ : Resveratrol induces cell cycle arrest via a p53-independent pathway in A549 cells. Mol Med Rep 11: 2459-2464, 2015.

18. Chiang SR, Lin CS, Lin HH, Shieh PC and Kao SH: Bergapten induces G1 arrest of nonsmall cell lung cancer cells, associated with the p53 mediated cascade. Mol Med Rep 19: 1972-1978, 2019.

19. Wang S, Hu Y, Yan Y, Cheng Z and Liu T: Sotetsuflavone inhibits proliferation and induces apoptosis of A549 cells through ROS-mediated mitochondrial-dependent pathway. BMC Complement Altern Med 18: 235, 2018.

20. Rukkijakan T, Ngiwsara L, Lirdprapamongkol K, Svasti J, Phetrak N and Chuawong P: A synthetic 2,3-diarylindole induces cell death via apoptosis and autophagy in A549 lung cancer cells. Bioorg Med Chem Lett 26: 2119-2123, 2016.

21. Keeratichamroen S, Lirdprapamongkol K and Svasti J: Mechanism of ECM-induced dormancy and chemoresistance in A549 human lung carcinoma cells. Oncol Rep 39: 1765-1774, 2018.

22. Hsu KC, Chen YF, Lin SR and Yang JM: iGEMDOCK: A graphical environment of enhancing GEMDOCK using pharmacological interactions and post-screening analysis. BMC Bioinformatics 12 (Suppl 1): S33, 2011.

23. Pettersen EF, Goddard TD, Huang CC, Couch GS, Greenblatt DM Meng EC and Ferrin TE: UCSF Chimera-a visualization system for exploratory research and analysis. J Comput Chem 25: $1605-1612,2004$

24. Liu M, Xiao C, Sun M, Tan M, Hu L and Yu Q: Parthenolide inhibits STAT3 signaling by covalently targeting Janus kinases. Molecules 23: 1478, 2018 .

25. Kupchan SM, Hemingway RJ, Karim A and Werner D: Tumor inhibitors. XLVII. Vernodalin and vernomygdin, two new cytotoxic sesquiterpene lactones from Vernonia amygdalina Del J Org Chem 34: 3908-3911, 1969.

26. Kupchan SM, Hemingway RJ, Werner D and Karim A: Tumor inhibitors. XLVI. Vernolepin, a novel sesquiterpene dilactone tumor inhibitor from Vernonia hymenolepis A. rich. J Org Chem 34: 3903-3907, 1969.

27. Laekeman GM, De Clerck F, Vlietinck AJ and Herman AG: Vernolepin: An antiplatelet compound of natural origin. Naunyn Schmiedebergs Arch Pharmacol 331: 108-113, 1985.

28. Zenebe MM, Dessie KB, Hana GM and Werkneh AA: Isolation, structural elucidation, and bioactivity studies of leaf extract of Vernonia amygdalina. Am J Appl Chem 3: 14-20, 2015.

29. Chukwujekwu JC, Lategan CA, Smith PJ, Van Heerden FR and Van Staden J: Antiplasmodial and cytotoxic activity of isolated sesquiterpene lactones from the acetone leaf extract of Vernonia colorata. S Afr J Bot 75: 176-179, 2009.

30. Erasto P, Grierson DS and Afolayan AJ: Bioactive sesquiterpene lactones from the leaves of Vernonia amygdalina. J Ethnopharmacol 106: 117-120, 2006.

31. Quitschke WW: Curcuminoid binding to embryonal carcinoma cells: Reductive metabolism, induction of apoptosis, senescence, and inhibition of cell proliferation. PLoS One 7: e39568, 2012.

32. Wong RS: Apoptosis in cancer: From pathogenesis to treatment. J Exp Clin Cancer Res 30: 87, 2011.

33. Ewald JA, Desotelle JA, Wilding G and Jarrard DF: Therapy-induced senescence in cancer. J Natl Cancer Inst 102: $1536-1546,2010$
34. Zhu H and Gooderham NJ: Mechanisms of induction of cell cycle arrest and cell death by cryptolepine in human lung adenocarcinoma a549 cells. Toxicol Sci 91: 132-139, 2006.

35. Chen J, Wang J, Lin L, He L, Wu Y, Zhang L, Yi Z, Chen Y, Pang X and Liu M: Inhibition of STAT3 signaling pathway by nitidine chloride suppressed the angiogenesis and growth of human gastric cancer. Mol Cancer Ther 11: 277-287, 2012.

36. Li J, Kent DG, Chen E and Green AR: Mouse models of myeloproliferative neoplasms: JAK of all grades. Dis Model Mech 4: 311-317, 2011.

37. Huang WW, Yang JS, Lin MW, Chen PY, Chiou SM, Chueh FS, Lan YH, Pai SJ, Tsuzuki M, Ho WJ and Chung JG: Cucurbitacin E induces G(2)/M phase arrest through STAT3/p53/p21 signaling and provokes apoptosis via Fas/CD95 and Mitochondria- dependent pathways in human bladder cancer T24 cells. Evid Based Complement Alternat Med 2012: 952762, 2012.

38. Zhou C, Ma J, Su M, Shao D, Zhao J, Zhao T, Song Z, Meng Y and Jiao P: Down-regulation of STAT3 induces the apoptosis and G1 cell cycle arrest in esophageal carcinoma ECA109 cells Cancer Cell Int 18: 53, 2018.

39. Kim JY, Choi JA, Kim TH, Yoo YD, Kim JI, Lee YJ, Yoo SY, Cho CK, Lee YS and Lee SJ: Involvement of p38 mitogen-activated protein kinase in the cell growth inhibition by sodium arsenite. J Cell Physiol 190: 29-37, 2002.

40. Kang N, Wang MM, Wang YH, Zhang ZN, Cao HR, Lv YH, Yang Y, Fan PH, Qiu F and Gao XM: Tetrahydrocurcumin induces $\mathrm{G} 2 / \mathrm{M}$ cell cycle arrest and apoptosis involving p38 MAPK activation in human breast cancer cells. Food Chem Toxicol 67: 193-200, 2014.

41. Lepley DM and Pelling JC: Induction of p21/WAF1 and G1 cell-cycle arrest by the chemopreventive agent apigenin. Mol Carcinog 19: 74-82, 1997.

42. Liu H, Li Z, Huo S, Wei $Q$ and Ge L: Induction of $G_{0} / G_{1}$ phase arrest and apoptosis by CRISPR/Cas9-mediated knockout of CDK2 in A375 melanocytes. Mol Clin Oncol 12: 9-14, 2020.

43. Siu WY, Yam CH and Poon RY: G1 versus G2 cell cycle arrest after adriamycin-induced damage in mouse Swiss3T3 cells. FEBS Lett 461: 299-305, 1999.

44. Sinisi A, Millán E, Abay SM, Habluetzel A, Appendino G, Muñoz E and Taglialatela-Scafati O: Poly-Electrophilic Sesquiterpene Lactones from Vernonia amygdalina: New members and differences in their mechanism of thiol trapping and in bioactivity. J Nat Prod 78: 1618-1623, 2015.

45. Hsieh FC, Cheng G and Lin J: Evaluation of potential Stat3-regulated genes in human breast cancer. Biochem Biophys Res Commun 335: 292-299, 2005.

46. Lirdprapamongkol K, Sakurai H, Abdelhamed S, Yokoyama S, Athikomkulchai S, Viriyaroj A, Awale S, Ruchirawat S, Svasti J and Saiki I: Chrysin overcomes TRAIL resistance of cancer cells through Mcl-1 downregulation by inhibiting STAT3 phosphorylation. Int J Oncol 43: 329-337, 2013.

47. Sun CY, Nie J, Huang JP, Zheng GJ and Feng B: Targeting STAT3 inhibition to reverse cisplatin resistance. Biomed Pharmacother 117: 109135, 2019.

48. Lankadasari MB, Aparna JS, Mohammed S, James S, Aoki K, Binu VS, Nair S and Harikumar KB: Targeting S1PR1/STAT3 loop abrogates desmoplasia and chemosensitizes pancreatic cancer to gemcitabine. Theranostics 8: 3824-3840, 2018.

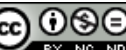

This work is licensed under a Creative Commons Attribution-NonCommercial-NoDerivatives 4.0 International (CC BY-NC-ND 4.0) License. 